\title{
Effectiveness and Tolerability of the Single-Pill Combination of Bisoprolol and Perindopril in Patients with Arterial Hypertension and Stable Coronary Artery Disease in Daily Clinical Practice: The STYLE Study
}

\author{
Sergey A. Boytsov (1) - Yuri P. Burtsev • Yunona V. Khomitskaya (1) · \\ Yuri A. Karpov (D) on behalf of The STYLE study investigators
}

Received: March 25, 2021 / Accepted: April 19, 2021

(C) The Author(s) 2021

\begin{abstract}
Introduction: Combination antihypertensive therapy is required by most patients to achieve guideline-recommended blood pressure (BP) goals. This study assessed the effectiveness and tolerability of bisoprolol/perindopril (Bis/Per) single-pill combination (SPC) in Russian patients with hypertension and coronary artery disease (CAD) treated in routine clinical practice.

Methods: STYLE (NCT03730116) was an openlabel, uncontrolled, prospective observational study conducted in patients who were already receiving Bis/Per SPC, switched to SPC from Bis or Per monotherapy, or switched from a free combination of Bis and Per. Primary endpoint criteria were assessed at 1 and 3 months and included change in mean office systolic/diastolic blood pressure (SBP/DBP), proportion
\end{abstract}

The STYLE study investigators are listed in the Acknowledgement section.

S. A. Boytsov · Y. A. Karpov ( $₫)$

Department of Angiology, National Medical

Research Center of Cardiology of the Ministry of

Health of Russia, Moscow, Russia

e-mail: yuri_karpov@inbox.ru

Y. P. Burtsev · Y. V. Khomitskaya

Department of Medical Affairs, Servier Russia,

Moscow, Russia achieving target BP $(<140 / 90 \mathrm{mmHg})$, and measures of antianginal effectiveness.

Results: The full analysis set comprised 1892 subjects. Mean age was $61.9 \pm 8.8$ years, $53.2 \%$ were women, and mean durations of hypertension and CAD were $12.5 \pm 7.9$ and $7.2 \pm 6.4$ years, respectively. Mean SBP/DBP decreased by $22.3 / 11.0 \mathrm{mmHg}$ and $31.5 /$ $15.9 \mathrm{mmHg}$ at 1 and 3 months, respectively ( $P<0.0001$ vs baseline). Target BP was achieved by $49.2 \%$ and $86.7 \%$ of patients at 1 and 3 months, respectively. Reductions in mean number of angina attacks and nitrate consumption and improvements in heart rate were statistically significant. Treatment was well tolerated.

Conclusion: Treatment of patients with hypertension and CAD with Bis/Per SPC for 3 months was associated with significant decreases in SBP/ DBP and a high proportion of patients achieving BP treatment goals. This was accompanied by an improvement in angina symptoms. Treatment was well tolerated in a broad patient population representative of those seen in everyday clinical practice.

Keywords: Angina; Arterial hypertension; Bisoprolol; Blood pressure; Coronary artery disease; Heart rate; Perindopril; Single-pill combination (SPC) 


\section{Key Summary Points}

Why carry out this study?

An optimal treatment for patients with hypertension and coronary artery disease (CAD) would lower blood pressure, manage the symptoms of angina, and improve cardiovascular outcomes in a single pill

Beta-blockers and angiotensin-converting enzyme inhibitors have demonstrated complementary actions, reducing cardiac output and inducing vasodilation. This study assessed the effectiveness and tolerability of a single-pill combination (SPC) of bisoprolol/perindopril in patients with hypertension and CAD treated in routine clinical practice

What were the study outcomes/conclusions?

Switching to or maintaining a bisoprolol/ perindopril SPC led to rapid and statistically significant reductions in blood pressure with $87 \%$ of patients achieving target blood pressure at 3 months

This was accompanied by an improvement in angina symptoms and reduction in use of short-acting nitrates

Treatment was well tolerated in a broad patient population representative of those seen in everyday clinical practice

\section{DIGITAL FEATURES}

This article is published with digital features, including a summary slide and an infographic, to facilitate understanding of the article. To view digital features for this article go to https:// doi.org/10.6084/m9.figshare.14433932.

\section{INTRODUCTION}

Hypertension and hypertension-mediated organ damage (HMOD) contribute considerably to disability and global mortality [1, 2]. Hypertension-induced structural and/or functional changes in major organs are associated with increased risks of a number of conditions including arrhythmias, coronary artery disease (CAD), myocardial infarction, and congestive heart failure.

Hypertension burden in Russia is one of the highest in the world [3], with significant associated economic costs [4]. In the frame of the Russian participation in the 2017 global May Measurement Month (MMM) initiative, 5660 individuals were screened of whom 2709 $(47.9 \%)$ were found to have hypertension [5]. This is in line with data from another Russian epidemiological study, ESSE-RF, where hypertension prevalence was $44.2 \%$ [6]. Among treatment-naïve patients, the prevalence of hypertension was $20.3 \%$, and among those receiving antihypertensive medication, 55.9\% had uncontrolled blood pressure. Comparison of the Russian results with worldwide 2017 MMM data revealed that Russian participants had a higher proportion of hypertension, comparable antihypertensive prescription rates, and worse hypertension control [5]. To improve hypertension control and cardiovascular outcomes, strategies therefore need to focus on levels of modifiable risk factors in the population and on encouraging patients to adhere better to lifestyle changes and prescribed treatments.

The most recent European Society of Cardiology (ESC)/European Society of Hypertension (ESH) and Russian guidelines for the management of arterial hypertension consider anyone with a blood pressure greater than $140 / 90 \mathrm{mmHg}$ a candidate for treatment, with a goal of $130 / 80 \mathrm{mmHg}$ or lower in most patients $[7,8]$. To achieve this target, a single-pill combination of two antihypertensive agents is recommended first-line in all patients except lowrisk grade I and the frail elderly [7].

Patients with HMOD are at very high risk of cardiovascular events, yet many struggle to 
achieve optimal control. Data from the EUROASPIRE IV study conducted in 24 European countries indicated that six out of ten patients with CAD were not reaching their blood pressure targets [9]. By combining antihypertensive agents with different modes of action, physicians can improve the likelihood of blood pressure targets being achieved and provide individuals with the best protection against HMOD or limit its progression.

An optimal treatment in patients with hypertension and CAD would combine betablockers that target hypertension driven by the sympathetic nervous system with angiotensinconverting enzyme (ACE) inhibitors that target hypertension driven by the renin-angiotensin-aldosterone system. This provides a comprehensive neuroendocrine blockade, reducing cardiac output at the same time as inducing vasodilation, thus managing the symptoms of angina as well as lowering blood pressure. Data on the cardiovascular benefits of such a combination have already been provided by the EUROPA trial, which randomized over 12,000 patients with stable CAD to perindopril or placebo $(62 \%$ of whom were on beta-blockers) [10]. The addition of perindopril to a betablocker was associated with a $24 \%$ reduction in relative risk of the combined primary endpoint (cardiovascular death, non-fatal myocardial infarction, and resuscitated cardiac arrest) compared with the beta-blocker/placebo group [11]. Similar findings were observed in a retrospective pooled analysis of patients from three large perindopril outcome trials (EUROPA, ADVANCE, and PROGRESS) who received perindopril or placebo and were already on beta-blocker therapy [12]. Hypertension and $\mathrm{CAD}$ are predominantly managed in the outpatient setting. Bisoprolol is the most used betablocker in patients with stable angina and hypertension in Russia (up to 48.9\%) [13], and perindopril is the most used ACE inhibitor in Russian patients with hypertension [14].

The STYLE observational study was conducted to obtain real-world data on the antihypertensive and antianginal benefits of using a single pill combination (SPC) of bisoprolol and perindopril in patients with hypertension and stable CAD treated in daily clinical practice.

\section{METHODS}

STYLE was a multicenter, open-label, prospective, observational, uncontrolled study conducted between November 2018 and October 2019 in Russian clinical practice. General practitioners and cardiologists with outpatient practices included adult patients with arterial hypertension and concomitant stable CAD (defined as stable class I-III angina according to the Canadian Cardiovascular Society [CCS] classification). Decisions on prescription of the SPC of bisoprolol and perindopril according to the summary of product characteristics (SmPC) were made before recruitment in the program.

Exclusion criteria were stable angina class IV or unstable angina within the past 6 months, a history of myocardial infarction or cerebrovascular accident within the past 3 months, New York Heart Association (NYHA) class III to IV heart failure, type 1 diabetes mellitus or decompensated type 2 diabetes mellitus, any serious decompensated concomitant diseases requiring regular medical treatment, inability to understand the nature of the program and follow the recommendations, participation in another study within 30 days of the start of the observational program, and any contraindications to ACE inhibitors and/or beta-blockers.

The study was performed in accordance with good clinical practice and the ethical principles derived from the revised Declaration of Helsinki. Institutional ethics committee approval was sought before performing the study and all patients provided written informed consent.

Subjects were requested to make three visits to the study site: an inclusion visit (V1), 1-month follow-up visit (V2), and 3-month follow-up visit (V3). At V1 the investigators collected patient demographic data as well as information on risk factors, history of cardiovascular events, blood pressure, resting heart rate (HR), angina functional class and number of angina attacks, presence of symptoms of heart failure and functional NYHA heart failure class, and current cardiovascular treatments. Data on systolic and diastolic blood pressure (SBP and DBP), and HR were collected at all three visits. Office blood pressure was measured 
on the right arm after $5 \mathrm{~min}$ of rest with the patient in a sitting position using the Korotkoff method. Three measurements were performed at 1-2 min intervals, after $5 \mathrm{~min}$ of rest. SBP, DBP, and HR values were taken as the mean of the last two readings. If there were differences between two consecutive measurements of SBP of $15 \mathrm{mmHg}$ or more, repeated measurements were performed. During the study, the investigators collected subjective data from patients on treatment adherence and tolerability. In addition, patients kept a diary in which they reported number of angina attacks, consumption of short-acting nitrates, and any adverse events. Quality of life was assessed at each visit by patients, using a $100-\mathrm{mm}$ visual analog scale (VAS) on which 0 was worst quality of life and 100 was quality of life associated with perfect health.

At the inclusion visit patients were on bisoprolol and perindopril SPC, or on free combination of bisoprolol and perindopril, or on bisoprolol and perindopril monotherapy with intention before inclusion in the study to switch to SPC. Patients received bisoprolol/ perindopril at one of the following five doses: $2.5 / 2.5 \mathrm{mg}, \quad 2.5 / 5.0 \mathrm{mg}, \quad 5.0 / 5.0 \mathrm{mg}, \quad 5.0 /$ $10.0 \mathrm{mg}$, or $10.0 / 10.0 \mathrm{mg}$.

The primary study endpoints included measures of antihypertensive and antianginal effectiveness including change in mean office SBP and DBP, proportion of patients achieving a target blood pressure of less than 140/90 mmHg (proportion of patients achieving a target BP of less than $130 / 80 \mathrm{mmHg}$ was added after publication of the ESC/ESH guidelines for the management of arterial hypertension in 2018 [7]), change in number of angina attacks per week, and change in consumption of short-acting nitrates. HR and correlations between changes in HR and number of angina attacks and consumption of short-acting nitrates were also assessed. Secondary endpoints included the effect of treatment on quality of life and assessment of treatment adherence. The latter was assessed using a non-validated questionnaire in Russian comprising six questions where the answer of "no" to all questions indicated good adherence, "yes" to one or two questions indicated minor adherence, and "yes" to three or more questions indicated non-adherence [15]. Subjective assessments of effectiveness and tolerability were also performed by both physicians and patients at V3. Adverse events were assessed at each visit and recorded in the patient diary.

\section{Statistical Analysis}

Data were analyzed using $\mathrm{R}$ statistical software [16]. All study parameters were presented using descriptive statistics including mean, standard deviation, 95\% confidence intervals, or as absolute number and relative frequency of occurrence of each possible value for qualitative or categorical variables. Analyses were performed on the full analysis set (FAS). Changes in the mean weekly dose of short-acting nitrates were evaluated only in patients with available values. Before and after treatment values with a normal distribution were compared using the Student's $t$ test for paired observations; the Wilcoxon non-parametric test was used for those that did not follow a normal distribution. A value of $P<0.05$ was considered statistically significant. Adverse events were assessed in all patients who received a dose of study drug.

\section{RESULTS}

A total of 370 GPs and cardiologists recruited 1909 patients to take part in the STYLE observational program. Seventeen patients did not meet the inclusion criteria and therefore 1892 patients were included in the FAS of whom 1873 completed the study. Reasons for withdrawal for 19 patients were patient's decisions $(n=4)$, adverse events $(n=3)$, did not attend follow-up visit $(n=2)$, lost to follow-up $(n=1)$, physician's decision $(n=1)$, and reason not stated $(n=8)$.

Demographic and baseline clinical characteristics are shown in Table 1 . Mean age was $61.9 \pm 8.8$ years. There were $874(46.2 \%)$ men and 1007 (53.2\%) women; no gender was indicated in 11 participants $(0.6 \%)$.

The mean SBP and DBP values at baseline were $\quad 158.3 \pm 14.6 \mathrm{mmHg}$ and $93.1 \pm 9.2 \mathrm{mmHg}$, respectively, and resting HR 
Table 1 Baseline patient demographics and clinical characteristics

\begin{tabular}{ll}
\hline & $\begin{array}{l}\text { Total population } \\
(\boldsymbol{n}=\mathbf{1 8 9 2})\end{array}$ \\
\hline Age (mean \pm SD, years) & $61.9 \pm 8.8$ \\
Gender, $n$ (\%) & \\
Men & $874(46.2)$ \\
Women & $1007(53.2)$ \\
Missing data & $11(0.6)$ \\
SBP (mean \pm SD, mmHg) & $158.3 \pm 14.6$ \\
DBP (mean \pm SD, mmHg) & $93.1 \pm 9.2$ \\
Heart rate (mean \pm SD, bpm) & $82.5 \pm 10.1$ \\
Hypertension, $n$ (\%) & \\
Grade 1 & $250(13.2)$ \\
Grade 2 & $1065(56.3)$ \\
Grade 3 & $548(29.0)$ \\
Duration of hypertension & $12.5(7.9)$ \\
(mean \pm SD, years) & \\
Angina functional class, $n(\%)$ & $138(7.3)$ \\
I & $1538(76.0)$ \\
II &
\end{tabular}

Table 1 continued

\begin{tabular}{ll}
\hline & $\begin{array}{l}\text { Total population } \\
(\boldsymbol{n}=\mathbf{1 8 9 2})\end{array}$ \\
\hline Chronic renal disease, $n(\%)$ & $247(13.1)$ \\
Concomitant therapy, $n(\%)$ & \\
ACE inhibitor & $231(12.2)$ \\
ARB & $51(2.7)$ \\
CCB & $444(23.5)$ \\
Diuretic & $695(36.7)$ \\
Beta-blocker & $278(14.7)$ \\
Imidazole receptor agonist & $50(2.6)$ \\
Trimetazidine & $650(34.4)$ \\
Ivabradine & $67(3.5)$ \\
Short-acting nitrate & $643(34.0)$ \\
Long-acting nitrate & $235(12.4)$ \\
Antithrombotic agent & $1486(78.5)$ \\
Statin & $1449(76.6)$ \\
\hline
\end{tabular}

was $82.5 \pm 10.1 \mathrm{bpm}$. The majority of patients $(85 \%)$ had grade 2 or 3 hypertension (defined as blood pressure higher than 160/100 and $180 / 110 \mathrm{mmHg}$, respectively), and mean duration of hypertension was $12.5 \pm 7.9$ years. CCS class I angina had been diagnosed in $23.6 \%$ of patients, class II in $61.1 \%$, and class III in $7.2 \%$. The mean duration of CAD was $7.2 \pm 6.4$ years.

In addition to hypertension, $75.6 \%$ had dyslipidemia, $15.8 \%$ had type 2 diabetes, $26.6 \%$ were current smokers, $66.0 \%$ did not perform regular physical exercise, and 38.9\% had a family history of cardiovascular disease. Concomitant cardiovascular diseases were prevalent: $84.2 \%$ had left ventricular hypertrophy, $76.0 \%$ had NYHA class I-II congestive heart failure, $26.2 \%$ had a history of myocardial infarction, $19.7 \%$ a history of coronary revascularization, and $7.3 \%$ a history of stroke or transient ischemic attack. 
At the baseline visit, $89 \%$ of patients $(n=1684)$ were already on SPC bisoprolol and perindopril, $1.7 \%(n=33)$ were on free combination of bisoprolol and perindopril followed by prescription of SPC, $7 \%(n=132)$ were on bisoprolol monotherapy followed by prescription of SPC, and $0.9 \% \quad(n=17)$ were on perindopril monotherapy followed by prescription of SPC. For 26 patients (1.4\%) the type of therapy with perindopril and bisoprolol was not described. All decisions on switching from free combination or monotherapy to SPC bisoprolol and perindopril were taken independently and before inclusion in the study. The most frequently prescribed SPC dose was 5.0/10.0 mg $(33.5 \%)$, followed by $5.0 / 5.0 \mathrm{mg}(26.3 \%)$, and $10.0 / 10.0 \mathrm{mg}(16.1 \%)$. The proportions of patients receiving these doses increased slightly at V2 $(38.8 \%, 28.5 \%$, and $22.1 \%$, respectively) and then remained relatively constant for the rest of the study (Table 2).

In addition to this treatment, patients were receiving a range of cardiovascular drugs including beta-blockers, calcium channel blockers, diuretics, ACE inhibitors and angiotensin receptor blockers, and imidazole receptor agonists (Table 1). Patients prescribed other antihypertensive regimens received the SPC in addition to their existing therapy. Statins were prescribed in $76.6 \%$, antithrombotic therapy (78.5\%), trimetazidine $(34.4 \%)$, ivabradine

Table 2 Number of patients receiving doses of the bisoprolol/perindopril single pill combination at each study visit

\begin{tabular}{lccc}
\hline Dose $(\mathbf{m g})$ & \multicolumn{3}{c}{ Number of patients } \\
\cline { 2 - 4 } & Visit $\mathbf{1}$ & Visit 2 & Visit 3 \\
\hline $2.5+2.5$ & 20 & 20 & 20 \\
$2.5+5.0$ & 19 & 18 & 19 \\
$5.0+5.0$ & 482 & 522 & 526 \\
$5.0+10.0$ & 614 & 712 & 706 \\
$10.0+10.0$ & 295 & 406 & 411 \\
No data & 462 & 195 & 191 \\
Total & 1892 & 1873 & 1873 \\
\hline
\end{tabular}

(3.5\%), short-acting nitrates $(34.0 \%)$, and longacting nitrates (12.4\%) (Table 1). During the study, no statistically significant changes in these concomitant treatments nor their doses were observed, except for statin treatment for which the number of patients taking atorvastatin $20 \mathrm{mg}$ or $40 \mathrm{mg}$ and simvastatin $10 \mathrm{mg}$ or $20 \mathrm{mg}$ increased.

There were no statistically significant changes between visits in the doses of other background antihypertensive treatment while patients were receiving the bisoprolol/perindopril SPC.

\section{Primary Effectiveness Parameters}

Mean SBP decreased from $158.3 \pm 14.6 \mathrm{mmHg}$ at baseline to $136 \pm 11.9 \mathrm{mmHg}$ at V2 $(22.3 \pm 13.1 \mathrm{mmHg}$ reduction $)$ and to $126.9 \pm 8.4 \mathrm{mmHg}$ at $\mathrm{V} 3(31.5 \pm 14.2 \mathrm{mmHg}$ reduction) reaching the target set by the new guidelines (Fig. 1). The reduction in SBP was statistically significant between baseline and V2 and baseline and V3 (both $P<0.0001$ ), but not between V2 and V3 suggesting that most of the SBP reduction occurred within the first month of treatment. Similarly, mean DBP decreased from $93.1 \pm 9.2 \mathrm{mmHg}$ at baseline to $82.1 \pm 7.6$ at $\mathrm{V} 2(11.0 \pm 9.1 \mathrm{mmHg}$ reduction $)$ and to $77.2 \pm 6.2$ at $\mathrm{V} 3(15.9 \pm 9.5 \mathrm{mmHg}$ reduction) (both $P<0.0001$ ) (Fig. 1). The difference between V2 and V3 did not reach statistical significance.

The proportion of patients achieving the target blood pressure level (SBP $<140 \mathrm{mmHg}$ and DBP $<90 \mathrm{mmHg}$ ) at V2 was $49.2 \%$ (Fig. 2). At V3 this had increased to $86.7 \%$. The proportion of patients meeting the target of less than $130 / 80 \mathrm{mmHg}$ was $20.1 \%$ at $\mathrm{V} 2$ and $31.9 \%$ at V3 (Fig. 2).

The average number of angina attacks per week was $3.7 \pm 8.5$ at baseline, $1.3 \pm 2.2$ at V2, and $0.5 \pm 1.2$ at V3. Reductions were statistically significant between baseline and V2 and baseline and V3 $(P<0.0001)$ (Table 3$)$. The mean consumption of short-acting nitrates (tablets/sprays) per week was reduced from $4.0 \pm 4.3$ at baseline to $2.1 \pm 2.4$ at V2, and $1.0 \pm 1.5$ at V3, which were statistically 


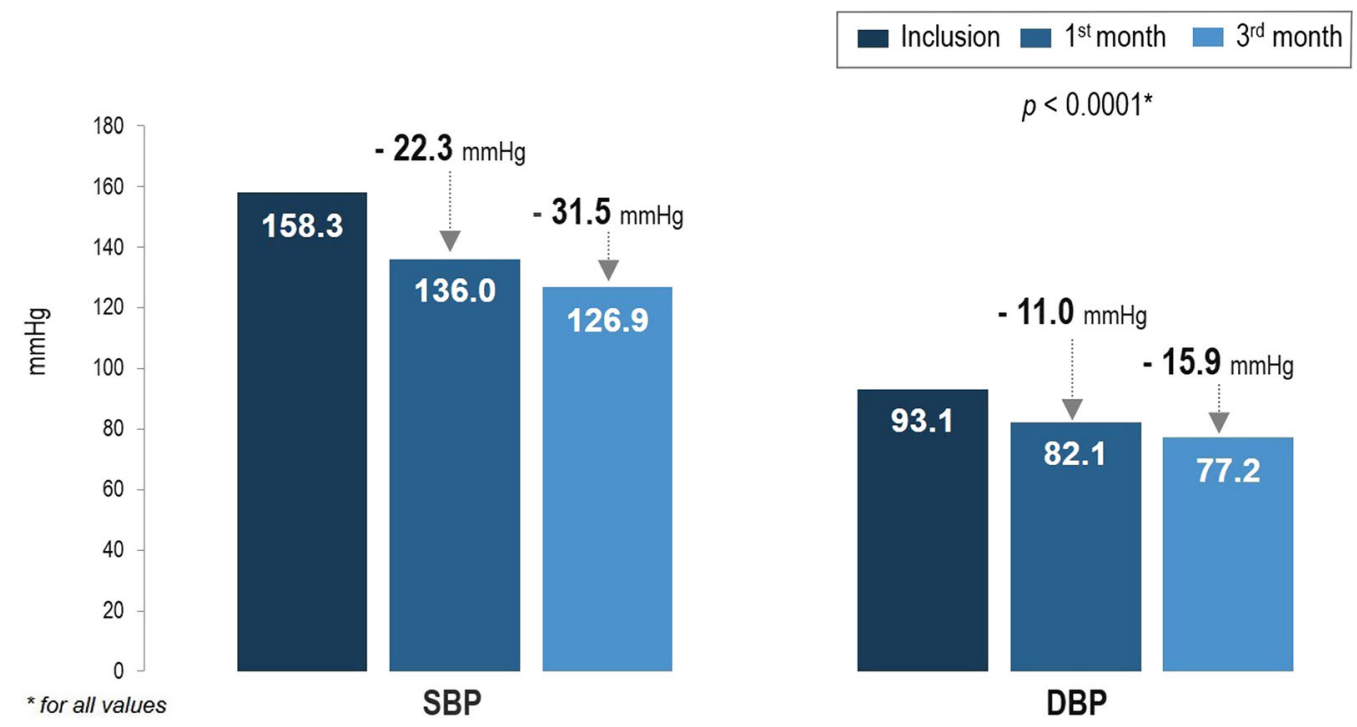

Fig. 1 Change in mean blood pressure at visit 2 (1 month) and visit 3 (3 months) compared with visit 1 (inclusion visit). For both SBP and DBP, changes were

statistically significant for visit 2 compared with visit 1 and for visit 3 compared with visit 1 (all $P<0.0001$ )
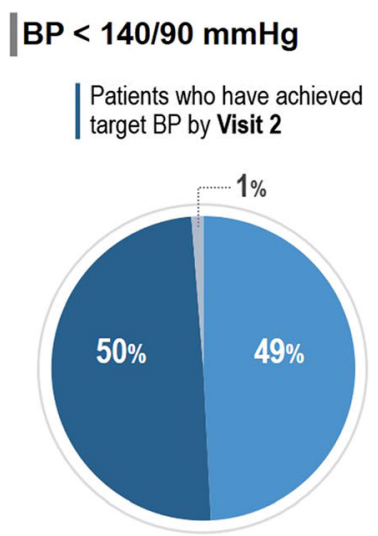

Patients who have achieved target BP by Visit 3

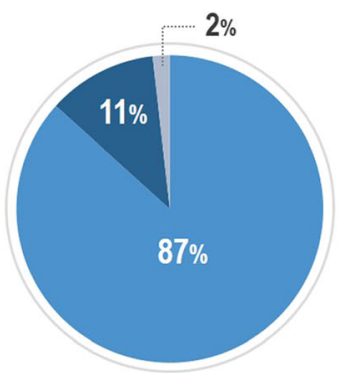

\section{BP $<130 / 80 \mathrm{mmHg}$}

Patients who have achieved target BP by Visit 3

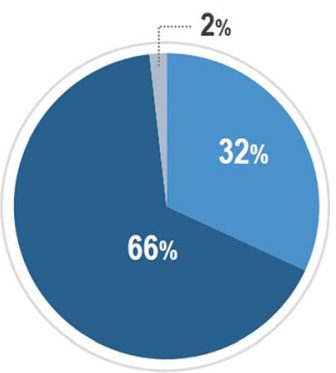

$\square$ Achieved $\square$ Not achieved No data

Fig. 2 Proportion of subjects achieving blood pressure targets at visit 2 (1 month) and visit 3 ( 3 months)

Table 3 Mean change in number of angina attacks per week between visits $(N=1892)$

\begin{tabular}{llll}
\hline Parameter & Visit $\mathbf{1 - 2}$ & Visit $\mathbf{1 - 3}$ & Visit 2-3 \\
\hline$N$ & 1842 & 1848 & 1858 \\
Mean & -2.4 & -3.2 & -0.8 \\
SD & 8.0 & 8.2 & 1.6 \\
$P$ value & $<0.0001$ & $<0.0001$ & \\
\hline
\end{tabular}

significant for V2 and V3 compared with baseline $(P<0.0001)$ (Table 4$)$.

\section{Secondary Effectiveness Parameters}

At baseline, the mean resting $\mathrm{HR}$ was $82.5 \pm 10.1 \mathrm{bpm}$. After 1 month of bisoprolol/ perindopril SPC, resting HR had decreased by $13.5 \pm 9.0 \mathrm{bpm}$ to $69.0 \pm 7.5 \mathrm{bpm}(P<0.0001)$, and after 3 months had decreased by $17.7 \pm 9.7 \mathrm{bpm}$ to $64.9 \pm 5.5 \mathrm{bpm}(P<0.0001)$ 
Table 4 Average change in weekly nitroglycerin consumption (tablets or aerosol doses) between visits $(N=1892)$

\begin{tabular}{llll}
\hline Parameter & Visit 1-2 & Visit 1-3 & Visit 2-3 \\
\hline$N$ & 867 & 534 & 525 \\
Mean & -2.9 & -4.1 & -1.3 \\
SD & 3.4 & 4.6 & 1.8 \\
$P$ value & $<0.0001$ & $<0.0001$ & \\
\hline
\end{tabular}

(Fig. 3). No significant correlation was found between the HR reduction and the reduction in the number of angina attacks in the periods between visits 2 and 1 , and visits 3 and 1 . A weak but statistically significant positive correlation was observed between the HR reduction and the number of angina attacks between V2 and V3 (the correlation coefficient was 0.047, $P<0.0001)$. The HR reduction during the study was also associated with a slight decrease in nitrate consumption in this cohort of patients with hypertension and stable CAD. The correlation coefficient was $0.039(P=0.004)$ for the period from visit 1 to visit $2,0.0617(P=0.002)$ for the period from visit 1 to visit 3 , and 0.0624
$(P<0.0001)$ for the period from visit 2 to visit 3.

At baseline the proportion of patients with resting HR less than $60 \mathrm{bpm}$ as recommended by guidelines was $1.5 \%$. However, an increase in patients achieving the target level of resting HR was observed at V2 and V3 (12.6\% and 24.7\%, respectively). Changing the dose of bisoprolol/ perindopril SPC had little effect on the reductions in the mean HR values (Table 5).

Treatment with the bisoprolol/perindopril SPC significantly improved patient quality of life according to the VAS with an increase in mean score from $47.2 \pm 17.4 \mathrm{~mm}$ at baseline to $67.9 \pm 14.3 \mathrm{~mm}$ at V2 $(P<0.0001)$ and $82.4 \pm 13.3 \mathrm{~mm}$ at V3 $(P<0.0001)$ (Fig. 4$)$.

At V2, just over half the participants (52.4\%) had minor adherence, $37.2 \%$ of patients had good adherence, while $10.1 \%$ of participants did not follow physicians' recommendations at all (non-adherent). At V3, the proportion of patients with good adherence had increased to $57.1 \%$, while the proportion of participants who were non-adherent had decreased significantly to $2.8 \%$. The proportion of patients with minor adherence decreased to $39.4 \%$. A subjective assessment of effectiveness and tolerability was also performed by both physicians

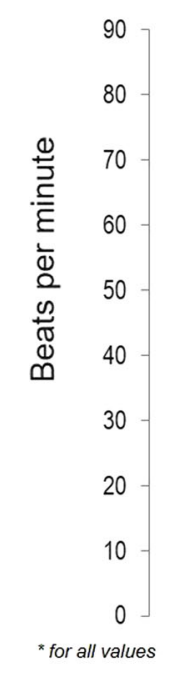

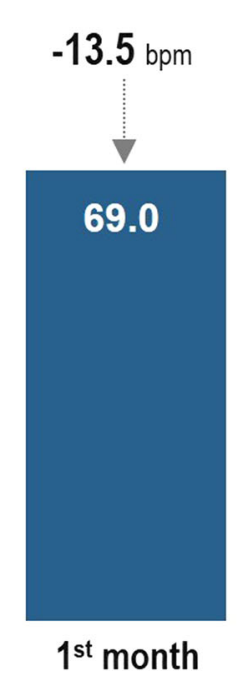

$$
p<0.0001^{*}
$$

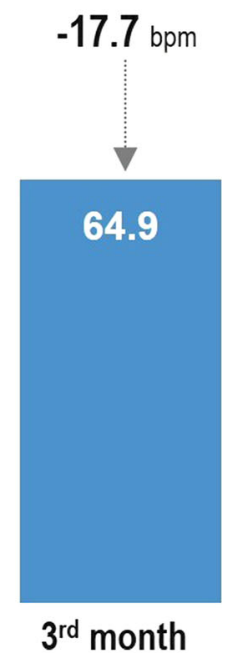

Fig. 3 Change in mean heart rate (HR) at visit 2 ( 1 month) and visit 3 (3 months) compared with visit 1 (inclusion visit) 
Table 5 Mean heart rate reduction according to single-pill combination dose

\begin{tabular}{llll}
\hline Dose $(\mathbf{m g})$ & \multicolumn{3}{l}{ Mean \pm SD heart rate reduction $(\mathbf{b p m})$} \\
\cline { 2 - 4 } & $\begin{array}{l}\text { Visit 3 vs } \\
\text { visit 1 }\end{array}$ & $\begin{array}{l}\text { Visit 2 vs } \\
\text { visit 1 }\end{array}$ & $\begin{array}{l}\text { Visit 3 vs } \\
\text { visit 2 }\end{array}$ \\
\hline $2.5+2.5$ & $-12(9.1)$ & $-10.1(8.8)$ & $-1.9(3.4)$ \\
$2.5+5$ & $-9.2(6)$ & $-7.8(7.3)$ & $-2.4(3.8)$ \\
$5+5$ & $-16.6(9.3)$ & $-13.1(8.7)$ & $-3.4(5.2)$ \\
$5+10$ & $-17.1(9.2)$ & $-12.9(8.3)$ & $-4.1(5.7)$ \\
$10+10$ & $-19.5(9.6)$ & $-14.3(9.1)$ & $-5.3(6.4)$ \\
$\begin{array}{c}\text { Correlation } \\
\text { coefficient }\end{array}$ & -0.1350 & -0.0632 & -0.1311 \\
\hline
\end{tabular}

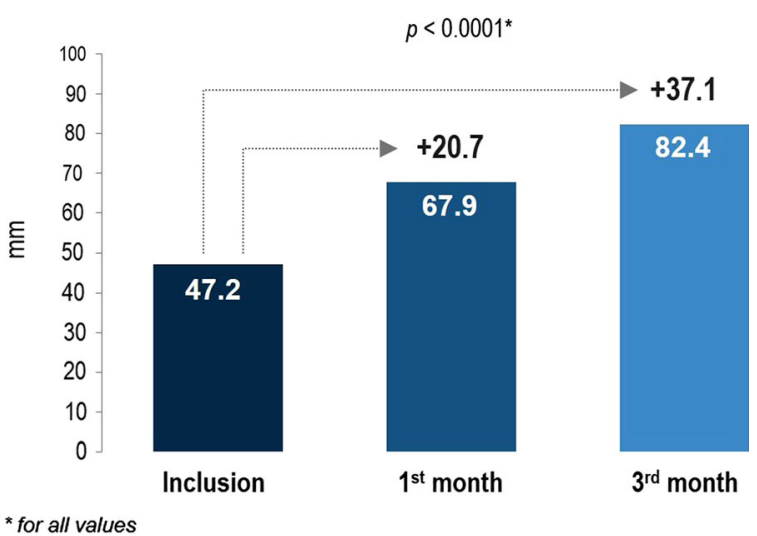

Fig. 4 Change in quality of life at visit 2 ( 1 month) and visit 3 (3 months) compared with visit 1 (inclusion visit). VAS visual analog scale

and patients at V3. Physicians reported treatment effectiveness was "excellent" in $65 \%$ of patients and "good" in $32 \%$. In comparison, patient ratings for treatment effectiveness were "excellent" in $54.5 \%$ and "good" in $41.4 \%$. Physicians rated tolerability as "excellent" in $68.2 \%$ of patients and "good" in $29.4 \%$. The proportions of patients reporting "excellent" or "good" tolerability were $58.0 \%$ and $38.5 \%$, respectively.

\section{Safety}

The profile of reported adverse events corresponded with the well-known safety profile of the individual drug components and characteristics of the included patients. No new safety issues were identified. During the study, physicians recorded nine adverse events in four patients $(0.2 \%)$. In three patients the adverse drug reaction resulted in withdrawal of bisoprolol/perindopril SPC. Two patients receiving the SPC at a dose of $5 \mathrm{mg} / 5 \mathrm{mg}$ experienced arterial hypotension with dizziness and bradycardia, one of them also had an episode of syncope. These events were considered to be causally related to study drug and in one patient resulted in the SPC being taken periodically and not daily, which did not comply with the instructions for medical use.

One patient experienced a dry cough and tingling throat during the treatment which was also treatment related. The fourth patient experienced a non-traumatic vertebral compression fracture that required hospitalization followed by death of unknown cause. This event was not related to study drug.

\section{DISCUSSION}

The results of the STYLE observational study provide important data on the characteristics of patients with hypertension and stable CAD treated in a Russian outpatient setting. Analysis of the baseline characteristics of this population revealed a high prevalence of cardiovascular disease risk factors and multiple HMOD. Despite this, mean blood pressure at baseline was $158 / 93 \mathrm{mmHg}$ and mean resting $\mathrm{HR}$ was $82.5 \pm 10.1 \mathrm{bpm}$, well above recommended targets [17]. Following the switch to or addition of bisoprolol/perindopril SPC to the patients' antihypertensive regimens, reductions in mean blood pressure of $22 / 11 \mathrm{mmHg}$ at $\mathrm{V} 2$ and $32 / 16 \mathrm{mmHg}$ at V3 were observed. At each visit the reductions were statistically significant compared with baseline, but not between the visits. This suggests that blood pressure reductions occurred early after initiation of treatment, an important consideration in a population at high cardiovascular risk. By V3, $86.7 \%$ of the study population had achieved the target blood pressure level of less than $140 / 90 \mathrm{mmHg}$, but as the most recent ESC/ESH 
guidelines were published during the study it was also decided to evaluate the proportion of patients achieving the new target of less than $130 / 80 \mathrm{mmHg}$. The proportion achieving this target was $31.9 \%$ at V3. This analysis was performed on the FAS and did not take into consideration factors such as age and treatment tolerance that can have an impact on target blood pressure goals. In the current study, treatment was well tolerated and so unlikely to be a factor. Two potential reasons for achievement of the new blood pressure goals in only a third of the study population are (1) that most physicians were still following the previous blood pressure goals (less than 140/90 $\mathrm{mmHg}$ ) in routine clinical practice; and (2) that a proportion of the patients were older than 65 years and had a higher target blood pressure range.

During the study there were no statistically significant changes in the concomitant antihypertensive treatments or their doses, nor in other types of concomitant medication such as statins. The changes in blood pressure observed were therefore likely a result of the addition of the SPC to the treatment regimen.

Although HR is not included in any cardiovascular risk algorithm, it remains an independent predictor of cardiovascular morbidity and fatal events [18], yet only $14.7 \%$ of patients were receiving a beta-blocker at baseline and only $3.5 \%$ were receiving ivabradine. These data corroborate findings from other observational studies and registry analyses $[19,20]$. In the CLARIFY registry, a large, international, observational, longitudinal registry of outpatients with stable CAD, nearly half the CAD registry population had a HR of at least $70 \mathrm{bpm}$ despite three quarters receiving treatment with betablockers [20]. Furthermore, a HR of at least $70 \mathrm{bpm}$ was found to be independently associated with a higher prevalence and severity of angina, and more frequent evidence of myocardial ischemia [20].

In patients with $\mathrm{CAD}, \mathrm{HR}$ control is the first and most important step to achieve symptomatic control of stable angina, and betablockers are a first-line therapy to achieve this goal. Following the addition of the SPC with a bisoprolol component, a statistically significant reduction in HR was observed at both the 1- and 3-month visits compared with baseline. In another Russian cross-sectional, observational study with a similar population (ATHENA, AchievemenT of target resting HEart rate on beta-blockers in patients with stable angiNA and hypertension), patients with a median duration of beta-blocker treatment of 24.0 months (range 2.0-257.0) had only slightly higher resting HR (68.8 bpm, range 48.0-109.7) vs $64.9 \mathrm{bpm}$ (range 46-100) after 3 months of treatment with bisoprolol/perindopril SPC [13].

Meanwhile, in the STYLE study, a higher proportion of patients achieved the resting HR of 55-60 bpm recommended by the 2019 ESC guidelines for the diagnosis and management of chronic coronary syndromes [17] after 3 months of SPC treatment-24.3\% in STYLE vs $15.5 \%$ in ATHENA [13]. This could possibly be due to the slightly higher doses of beta-blockers used in STYLE. A rather low proportion of HR goal achievement in both studies can be explained by the fact that beta-blockers were used in low doses compared with those used in landmark clinical trials [21]. However, they correspond to the daily beta-blocker doses reported in a pan-European observational study of patients with stable angina [22]. A possible explanation of HR non-achievement is undertitration of beta-blocker dose because of adverse event fears and de-prioritization of $\mathrm{HR}$ as a treatment target for stable angina. Meanwhile, correlation coefficients between the reduction in HR and dose of bisoprolol/perindopril SPC were negative and close to 0 ; therefore, changing the dose of bisoprolol/perindopril SPC had little effect on reductions in mean HR values.

The addition of bisoprolol/perindopril SPC to the treatment plan also led to a reduction in the number of angina attacks and short-acting nitrate consumption, and this reduction was again statistically significant between baseline and the individual treatment visits. Furthermore, a weak but statistically significant positive correlation was observed between HR reduction and short-acting nitrate consumption. These data confirm findings from the ATHENA study in which patients achieving target HR had a significantly lower frequency of nitroglycerin-only administration compared 
with patients not achieving target $(1.5 \%$ vs 3.0\%, $P<0.045)$ [13].

Angina has an adverse effect on quality of life because of factors such as pain, limited exercise tolerance, and poor general health status [23]. Any reduction in the frequency or severity of angina symptoms would therefore be expected to improve quality of life as long as it was not associated with other adverse effects. In the current study, treatment with the bisoprolol/perindopril SPC significantly improved patient quality of life according to the VAS with an increase in mean score by $20.7 \mathrm{~mm}$ between baseline and V2, and an increase by $35.2 \mathrm{~mm}$ between baseline and V3; a change by $10 \mathrm{~mm}$ on a $100-m m$ VAS is considered clinically significant [24].

In the past few years greater emphasis has been placed on the prescription of effective pharmacological interventions that promote patient adherence [7, 25]. Combining agents with complementary mechanisms of action into a single pill is one solution that offers several advantages over the individual components taken separately [26]. These include more rapid reductions in blood pressure, a greater likelihood of achieving treatment targets, improved tolerability compared with uptitrating the dose of single agents, and a simplified dosing regimen, all of which favor adherence to the treatment [27-29]. This was reflected in the current study with adherence increasing throughout the study so that at V3, $57.1 \%$ had good adherence and $39.4 \%$ minor adherence; only $2.8 \%$ were non-adherent, perhaps owing to the multiple concomitant medications they were taking. Only three patients experienced treatment-related adverse events that resulted in study drug withdrawal. In addition, physicians confirmed tolerability of the single-pill combination was "good" to "excellent" in 97\% of patients, which was corroborated by $96.5 \%$ of patients.

This study was subject to the inherent limitations of observational studies, which include sample bias, incomplete response data, as well as to the potential inaccuracy of self-reported behavior. As an observational study without a control arm, blinding, and no randomized treatment allocation, this study does not attempt to make any causal inferences about treatment effect. In addition, the 3-month duration of the study, while being sufficient to observe an effect of the SPC on blood pressure and HR, was not long enough to provide any information on cardiovascular events and longterm adverse effects. Nevertheless, the population sample size was large and the findings have important implications for the treatment of a wide range of patients with hypertension and stable CAD in clinical practice.

\section{CONCLUSION}

The STYLE observational study results support the addition of a bisoprolol/perindopril SPC to standard antihypertensive therapy to simultaneously reduce blood pressure and $\mathrm{HR}$ in patients with hypertension and stable CAD and to allow more patients to achieve blood pressure treatment goals. The beneficial effects of the SPC on these risk factors were accompanied by improvements in angina symptoms and quality of life. The treatment was well tolerated in a broad patient population representative of those seen in everyday clinical practice. Meanwhile, these data indicate that physicians should pay more attention to resting HR management in patients with stable angina.

\section{ACKNOWLEDGEMENTS}

The authors thank the participants of the study. The STYLE study investigators: Kagramyan IK, Morukova DF, Hondzaeva PT, Borodin AS, Zarechneva TA, Mesheryakov DE, Tullaeva OG, Kvasova NA, Serebryakov NV, Beketova AI, Matveeva HS, Livova SN, Bikeeva LV, Molchanova IV, Korneeva ON, Abu-Aldjadel MM, Papirina MG, Kolchurina AV, Petrakova TA, Chistyakova EN, Hartova NV, Kucheruk NS, Rustamova KT, Grigorieva EA, Fillipov VL, Baitova EJ, Gavrikova NV, Hakieva MV, Zinovieva IE, Mezina LN, Adamyana MM, Profatilova GV, Ustinova EV, Ivanchenko GM, Nurieva AN, Volodenkova EU, Zagidova FZ, Pahomova NI, Ualichamova AU, Popova MS, Chrulenko SB, Orozalieva GM, Zhalsareva IS, Hodzaeva AU, 
Kulieva AZ, Pesenko OP, Kanahina AV, Baharchieva M.S-A, Koshrokova MA, Chugunova II, Orlov LA, Zarubina MO, Skurtul TV, Fagradyan LM, Sabitova OV, Mihailov GV, Demianova EU, Shilina EA, Nadtochieva VB, Egorenko EA, Gusova AK, Turovceva EP, Semenova DV, Spiridonov IG (Moscow), Zolotareva EA, Grosheva OV, Kotova NN, Emelianova EB, Sipilina TA, Sudareva NV (Yaroslavl), Lukovskaia AA, Redkova NN, Solodchuk EV (Ivanovo), Belyaeva US, Orlyanskaya YV (Kostroma), Kotlyarova MV, Timofeeva IV, Ryabova NI (Vladimir), Druzinin AS (Murom), Dubinskaya RE (Aleksandrov), Dmitrieva AV (Kovrov), Lutikova ES (Deviatkino), Pantiukhova VV (Volhov), Mannanova EV (Viborg), Dubrovina IE, Lisic NN (Tosno), Novoshenina AU (Sosnovi Bor), Shafranskaya RP, Laverichev AU, Averianova EL (Pskov), Mamedova AA (Velikie Luki), Alekseeva ND (Sebej), Zhukova UV, Andreeva SG, Levshun IV, Tatarskaya RV, Petrova ES (Velikiy Novgorod), Folomova SM, Smirnova OV, Pavlova EG, Luchko AI, Bolshakova EV, Marzoev SA, Aksenova NM, Trotsuk OV, Michailenko IA, Rindin RA, Borisov AE, Lenchik TS, Aleksandrova EV, Yakovlev MS, Vasilieva LB, Ziguleva IN, Hmelevskaya IA, Sosnovskaya OS, Ustinova DA, Liakova NN, Abrosimova AO, Amrosimovna AO, Shipanova IV, Belikova EI, Yablokova AV, Bondarenko IS, Petrenko UV, Leontieva ML, Pitinova EV, Osinceva YE, Morozova NN, Gurina IP, Semenova EV, Pahomova AL, Malikh ER (St. Petersburg), Levchenko GI, Kurdoglyan EV, Abdulova GH, Harina ON, Voynova NA (Kaliningrad), Vedeneeva OI, lialushkina OM (Petrozavodsk), Belyaeva TS (Novodvinsk), Timohina AA, Bestuzheva TV, Agafonova UA, Shendrik SN, Nikulina IV, Anisimova NV (Archangelsk), Serebryakova AA, Konovalova GV, Sharbatova EA, Zabelina MV (Vologda), Gonta VA, Grishechkina E, Hader NV, Boykova ES (Murmansk), Naubreyt KS (Severodvinsk), Gvozdareva OE, Panfilova NL, Kirilchenko EV, Frolenkova AA (Siktivkar), Lemeshko NP, Timofeeva NA, Kazanceva EV, Seoeva ES (Briansk), Nikiticheva VG, Motileva EA, Sitova TU, Buts TV (Kursk), Ivanchikova EV, Sosnovskih OI, Petrova NS, Kozmenko AV (Kaluga), Vinogradova KV, Kondratova EG, Gribanova UV, Zarikova SV (Orel), Vlasova OL,
Zhukova NA, Berleva OA, Glazkova IU (Smolensk), Kulchickaya OV, Ivanova OA, Oleshkevich EV, Aleksandrova VN, Kirichenko VV, Yasirova OA, Klimenieva LA, Matukhina OS, Merkhi AV, Chernish TV, Kolodina MV (Krasnodar), Kumbieva MB (Baksan), Fomenko OV (Georgievsk), Cherneva OT, Osipova VA (Piatigorsk), Popravko AA (Tuapse), Selisheva EV, Selivanova/Mazmanova, Chernyshev AV, Topchian GG (Sochi), Zuravleva IV (Izobilniy), Naumova EN, Kurkchan DS, Trusilkina VN (Stavropol), Bekurina SA (Novorosiysk), Anohina OV (Srednyaya Ahtuba), Kotlova AA (Volzskiy), Titovskaya NA, Mesheryakova OI, Gordievskaya AD, Shvedov AA, Nepokritova OA, Atamanchuk NM, Zotova OP, Shinkarenko AN (Volgograd), Burtseva VU (Shahti), Dzurich TA, Bobina OV, Matveeva OV, Mazrukho MK, Akopian AO, Abuzova EE, Egorov VN, Setegeva TN, Kutsenko TV, Buligina ED, Panchenko NN, Tolstokoneva TP, Lyashenko AI (Rostobv-naDonu), Ostapenko DE (Bataysk), Pastukhova EA, Varikasha EV, Lukerina OI, Gadomskaya EN, Krapivina LV (Simhperopol) Bidichenko AA, Nikitina OO, Skarga OV, Ovcharuk YV, Bagirova ND (Sevastopol), Tishina SA, Abrosimova AA, Mironova TV, Ulitina UU, Evseeva NM, Ksenofontova MA, Monachova AI, Ulianova TM, Kuzovkova SA, Knyazeva OA, Fedulova TN, Cheremina SL, Fedorova SN, Marinina OA (Nizniy Novgorod), Chaadaeva MI, Grechishkina OA, Kichigina TM, Adonina TS, Stolipina EA (Penza), Posashkova EI, Stepanova VS, Egorova ME, Khalimbaeva RN, Petrosyan VA, Zakirova VA, Rahmatullina RN (Kazan), Kusnecova IA, Zakirov AM, Lepihin IA, Buslaev PA, Kusnecova IA, Zakirov AM, Lepihin IA, Buslaev PA (Izevsk), Galimova GG, Shagiahmetova NN, Bidzinashvili RI, Tarzimanova US, Murasova RI, Galyamova ER, Petrova EA (Ufa), Bogdanov IA, Potehina UA, Goleva VS, Merslyakova SA, Kaplun TV, Drondina YS, Novoselova OM (Perm), Petrova EA, Ivanova UA, Borodkin AV, Ponomarev DS, Beschetnova TA (Tambov), Belova NI, Samarceva YN, Kashicina SP, Malashkina AV, AksenovaNV (Ryazan), Kuznecova AM, Morozova IV, Gorchalov KS, Senina EA, Zubareva LA (Tula), Orlyachenko TP, Gorelikov YA, Terechova AV, Bukreeva VS, Ovchinnikova SV (Lipeck), Volkova OO (Cheboksary), 
Kuzeina SS, Panfilova MV, Chernova TA, Kulahmetova RG (Nabereznye Chelny), Milnikova OL, Bessergeneva OL, Zikova LV, Nazmieva AZ (Kirov), Paholkina NA (Angardsk), Baranova TV (Shelehov), Sosnovskaya VS, Paholkina NA, Vasileva EN, Baranova TV, Ushkina GK, Dubinina UV, Petrova TV (Irkutsk), Mlechkova US (Zheleznogorsk), Shelehova MB, Danisheva LN, Minina IL, Hamraeva EH, Bosikh AO, Bakhova AA, Vasilieva IV, Belova VA (Krasnoyarsk), Kuzagildina AS, Usupova EI, Kostyleva EV, Tolkacheva AE, Strunina TI, Oreshuk GV (Chelyabinsk), Maksimchuk OV, Pochkanova IV, Khatlubey SL, Kozlova NV (Vladivostok), Urkovskaya NG, Leonova EA, Kulikova EA, Verhovceva UO, Simanova MS, Vafanova UV, Grebneva IU, Gerent GY, Poselova NV, Pestina MV, Zhuravleva EG, Goryachuk NN, Kalmazova IA (Ekaterinburg), Maneeva ID, Gavrilova NV, Dammer AI, Politova LV, Ivanova SV, Permyakova OV (Tomsk), Sahmaradze TA, Tarasova VL, Popova IV, Azamatova GR, Dvadnenko AV, Korabelnikova OV, Kovalchuk VA, Degtyarev AV, Kuznecova EA, Berezhnaya OA (Novosibirsk), Umakhanova DB (Nefteugansk), Glinskih IV, Gunzinov UD (Surgut), Dadik MS, Abakumova AS (Hanti-Mansiisk), Akhshiyatova NI, Yamova $\mathrm{AA}$, Isaeva BD, Chehoeva DV (Tumen), Berezovskaya LV, Larionova AP, Tabak AA, Volokonceva AL, Dorovko AV, Gudilin VA, Gaas IA (Omsk), Krestova OS, Evdokimova NA, Gaan NG, Ivanova IV, Krikunova ZP, Ryazanceva LG, Isakov LK (Kemerovo), Khalturina IG, Filatova TA, Kiseleva EV, Ivanov SV, Kolyasev IN (Barnaul), Pantukhina OV, Makhanov AV, Chigisova AN (Novokuzneck), Sokhaneva TV (Prokopievsk).

Funding. This study was funded by Servier, Russian Federation. The journal's rapid service fee was funded by Servier, France.

Medical Writing, Editorial, and Other Assistance. Editorial assistance for this paper was provided by Jenny Grice, Le Prioldy, France. This assistance was funded by Servier, France.

Disclosures. Yuri A. Karpov, Yuri P. Burtsev, Yunona V. Khomitskaya and Sergey A. Boytsov were scientific coordinators of this study. Yuri A. Karpov has received honoraria from Servier as a speaker. Sergey Boytsov has no conflicts of interest relevant to the content of this article. Yuri P. Burtsev and Yunona V. Khomitskaya are Servier Russia employees.

Data Availability. The datasets generated and/or analyzed for this study are not publicly available as they include medical records of patients from a secondary source.

Authorship. All named authors meet the International Committee of Medical Journal Editors (ICMJE) criteria for authorship for this article, take responsibility for the integrity of the work as a whole, and have given their approval for this version to be published.

Authors' Contributions. All authors had full access to all of the data in this study and take complete responsibility for the integrity of the data and accuracy of the data analysis.

Compliance with Ethics Guidelines. The study was performed in accordance with good clinical practice and the ethical principles derived from the revised Declaration of Helsinki. Intradisciplinary ethics committee approval was sought before performing the study (protocol \# 08-18 dated 05 October 2018). All patients provided written informed consent. All authors provide their consent for this article to be published.

Open Access. This article is licensed under a Creative Commons Attribution-NonCommercial 4.0 International License, which permits any non-commercial use, sharing, adaptation, distribution and reproduction in any medium or format, as long as you give appropriate credit to the original author(s) and the source, provide a link to the Creative Commons licence, and indicate if changes were made. The images or other third party material in this article are included in the article's Creative Commons licence, unless indicated otherwise in a credit line to the material. If material is not included in the article's Creative Commons licence and your intended use is not permitted by statutory 
regulation or exceeds the permitted use, you will need to obtain permission directly from the copyright holder. To view a copy of this licence, visit http://creativecommons.org/licenses/by$\mathrm{nc} / 4.0 /$.

\section{REFERENCES}

1. GBD 2015 Risk Factors Collaborators. Global, regional, and national comparative risk assessment of 79 behavioural, environmental and occupational, and metabolic risks or clusters of risks, 1990-2015: a systematic analysis for the Global Burden of Disease Study 2015. Lancet. 2016;388(10053):1659-724.

2. Forouzanfar MH, Liu P, Roth GA, et al. Global burden of hypertension and systolic blood pressure of at least 110 to $115 \mathrm{~mm} \mathrm{Hg}, 1990-2015$. JAMA. 2017;317(2):165-82.

3. Leon DA, Malyutina S, Kudryavtsev AV, et al. Dissecting hypertension in Russia: identifying aetiological and behavioural factors associated with treatment and control. Eur J Pub Health. 2018. https://doi.org/10.1093/eurpub/cky212.876.

4. Kontsevaya A, Kalinina A, Oganov R. Economic burden of cardiovascular diseases in the Russian Federation. Value Health Reg Issues. 2013;2(2): 199-204

5. Rotar O, Konradi A, Tanicheva A, et al. May measurement month 2017 in Russia: hypertension treatment and control, Europe. Eur Heart J Suppl. 2019;21(Suppl D):D101-3.

6. Shalnova SA, Drapkina OM. Contribution of the ESSE-RF study to preventive healthcare in Russia. Cardiovasc Therapy Prevent. 2020;19(3):2602.

7. Williams B, Mancia G, Spiering W. 2018 ESC/ESH Guidelines for the management of arterial hypertension. Eur Heart J. 2018;39(33):3021-3104.

8. Kobalava ZD, Konradi AO, Nedogoda SV, Shlyakhto EV, Arutyunov GP, Baranova EI, et al. Arterial hypertension in adults. Clinical guidelines 2020 . Russ J Cardiol. 2020;25(3):3786.

9. Kotseva K, De Bacquer D, De Backer G, et al. Lifestyle and risk factor management in people at high risk of cardiovascular disease. A report from the European Society of Cardiology European Action on Secondary and Primary Prevention by Intervention to Reduce Events (EUROASPIRE) IV cross- sectional survey in 14 European regions. Eur J Prev Cardiol. 2016; 23(18):2007-18.

10. Fox KM, EURopean trial on reduction of cardiac events with Perindopril in stable coronary Artery disease Investigators. Efficacy of perindopril in reduction of cardiovascular events among patients with stable coronary artery disease: randomised, double-blind, placebo-controlled, multicentre trial (the EUROPA study). Lancet. 2003;362(9386): 782-8.

11. Bertrand ME, Ferrari R, Remme WJ, Simoons ML, Fox KM. Perindopril and $\beta$-blocker for the prevention of cardiac events and mortality in stable coronary artery disease patients: a EUropean trial on Reduction Of cardiac events with Perindopril in stable coronary Artery disease (EUROPA) subanalysis. Am Heart J. 2015;170(6):1092-8.

12. Brugts JJ, Bertrand $M$, Remme $W$, et al. The treatment effect of an ACE-inhibitor based regimen with perindopril in relation to beta-blocker use in 29,463 patients with vascular disease: a combined analysis of individual data of ADVANCE, EUROPA and PROGRESS trials. Cardiovasc Drugs Ther. 2017;31(4):391-400.

13. Kobalava Z, Khomitskaya Y, Kiyakbaev G, ATHENA trial investigators. AchievemenT of target resting HEart rate on beta-blockers in patients with stable angiNA and hypertension (ATHENA) in routine clinical practice in Russia. Curr Med Res Opin. 2014;30(5):805-11.

14. Leonova MV, Steinberg LL, Belousov YB, et al. Results of pharmacoepidemiologic study of arterial hypertension Pifagor IV: physicians compliance. Russ J Cardiol. 2015;1(117):59-66.

15. Girerd X, Radauceanu A, Achard JM, et al. Evaluation of patient compliance among hypertensive patients treated by specialists. Arch Mal Coeur Vaiss. 2001;94(8):839-42 (Article in French).

16. R Core Team. R: a language and environment for statistical computing. 2013. R Foundation for Statistical Computing, Vienna, Austria. http://www.Rproject.org.

17. Knuuti J, Wijns W, Saraste A, et al. 2019 ESC Guidelines for the diagnosis and management of chronic coronary syndromes: the Task Force for the diagnosis and management of chronic coronary syndromes of the European Society of Cardiology (ESC). Eur Heart J. 2020; 41(3):407-7.

18. Julius S, Palatini P, Kjeldsen SE, et al. Usefulness of heart rate to predict cardiac events in treated patients with high-risk systemic hypertension. Am J Cardiol. 2012;109:685-92. 
19. Zugck C, Martinka P, Stöckl G. Ivabradine treatment in a chronic heart failure patient cohort: symptom reduction and improvement in quality of life in clinical practice. Adv Ther. 2014;31(9): 961-74.

20. Steg PG, Ferrari R, Ford I, et al. Heart rate and use of beta-blockers in stable outpatients with coronary artery disease. PLoS One. 2012;7(5):e36284.

21. von Arnim $\mathrm{T}$, The TIBBS Investigators. Medical treatment to reduce total ischemic burden: total ischemic burden bisoprolol study (TIBBS), a multicenter trial comparing bisoprolol and nifedipine. J Am Coll Cardiol. 1995;25:231-8.

22. Daly CA, Clemens F, Sendon JL, et al. Inadequate control of heart rate in patients with stable angina: results from the European heart survey. Postgrad Med J. 2010;86:212-7.

23. Brorsson B, Bernstein SJ, Brook RH, Werkö L. Quality of life of patients with chronic stable angina before and four years after coronary revascularisation compared with a normal population. Heart. 2002;87:140-5.

24. Vautier S. Measuring change with multiple visual analog scales: application to tense arousal. Eur J Psychol Assess. 2011;27(2):111-20.
25. Whelton PK, Carey RM, Aronow WS, et al. 2017 ACC/AHA/AAPA/ABC/ACPM/AGS/ APhA/ASH/ ASPC/NMA/PCNA guideline for the prevention, detection, evaluation, and management of high blood pressure in adults: executive summary: a report of the American College of Cardiology/ American Heart Association Task Force on Clinical Practice Guidelines. Hypertension. 2018;71(6): 1269-324.

26. Thomopoulos C, Katsimagklis G, Archontakis S, Skalis G, Makris T. Optimizing the management of uncontrolled hypertension: what do triple fixeddose drug combinations add? Curr Vasc Pharmacol. 2017;16:61-5.

27. Parati G, Kjeldsen S, Coca A, Cushman WC, Wang J. Adherence to single-pill versus free-equivalent combination therapy in hypertension. Hypertension. 2021;77:692-705.

28. Egan BM, Bandyopadhyay D, Shaftman SR, Zhao Y, Yu-Isenberg KS. Initial monotherapy and combination therapy and hypertension control the first year. Hypertension. 2012;59(6):1124-31.

29. Bahiru E, de Cates AN, Farr MR, et al. Fixed-dose combination therapy for the prevention of atherosclerotic cardiovascular diseases. Cochrane Database Syst Rev. 2017;3:009868. 